Pacific Journal of Mathematics

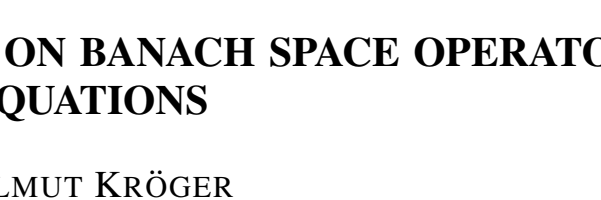




\title{
PADÉ APPROXIMANTS ON BANACH SPACE OPERATOR EQUATIONS
}

\author{
HELMUT KRÖGER
}

\begin{abstract}
We examine an operator equation with a linear compact kernel in a Banach space and the Padé Approximant of its solution under a functional. We give a sufficient condition for convergence of a subsequence of Padé Approximants to the solution.
\end{abstract}

1. Introduction. If one is handling the Padé Approximation technique in multi-particle scattering theory one is interested in convergence. For the two-body case the scattering problem can be formulated as an operator equation with a compact kernel in Hilbert space. Baker [1] proved a result on the convergence of Padé Approximants derived from an operator equation in Hilbert space. Pointwise convergence of a series of Padé Approximants is established for solutions of operator equations as for the two-body scattering partial wave decomposed Lippmann Schwinger kernel and for trace class and compact operators under assumptions on subspace projection sequences. Going over to more particles one usually works in Banach spaces. In the three-particle case Faddeev [4] established an operator equation with compact kernels in a certain Banach space.

Baker's investigation is not easy to generalize onto Banach spaces because of the use of orthogonal projections. Nevertheless we prove a similar result which is mainly based on the properties of cyclic subspaces generated by the inhomogeneity $g$ appearing in the operator equation and the kernel $A$, which is performed in $\S 2$.

In $\S 3$ we go over to Hilbert space. Our proposition can be formulated by means of the aperture of two subspaces, as defined by Nagy [8], Krein [6], Krasnoselskii [7]. Finally we discuss cases of validity.

2. Convergence theorem. Let us first present definitions. For standard notation used here see [3], [10], [12].

$B$ is a Banach space, $B^{*}$ its continuous dual space, $A$ a linear compact operator mapping $B$ into $B, A^{*}$ the adjoint, $g$ is an element of $B, h^{*}$ an element of $B^{*}$. Let $\lambda$ be a complex number and for $\lambda \neq 0$ let $\lambda^{-1}$ be an element of $\rho(A)$, the resolvent set of $A$. The operator equation is

$$
f=g+\lambda A f .
$$

A unique solution exists. 
$S_{g}^{(n)}$ is the linear span of the $A^{i} g, i=0,1, \cdots, n$.

$S_{g}$ the closed hull of the union of all $S_{g}^{(n)}$.

$T_{h^{*}}^{(n)}$ the linear span of the $A^{* i} h^{*}, i=0,1, \cdots, n$

$T_{h^{*}}$ the closed hull of the union of all $T_{h^{*}}^{(n)}$.

We assume $S_{g}, T_{h^{*}}$ to be infinite dimensional. We use the definition and properties of the Padé Approximant given by Zinn-Justin [13]. Let $f(z)$ be an analytic function defined by its Taylor series

$$
f(z)=\sum_{n=0}^{\infty} a_{n} z^{n}
$$

The Padé Approximant $f^{[n, m]}(z)$ of $f(z)$ is the following rational fraction

$$
f^{[n, m]}(z)=\frac{P_{n}(z)}{Q_{m}(z)}=f(z)+O\left(z^{n+m+1}\right) .
$$

The solution $f$ of $(2.1)$ can be expanded in a formal power series

$$
f(\lambda)=g+\lambda A g+\lambda^{2} A^{2} g+\cdots .
$$

It is well known [12] that the Neumann series converges to $f$ for $|\lambda|<1 /\|A\|$.

Analoguously $\left(h^{*}\right)(f)$ can be formally expanded

$$
\left(h^{*}\right)(f(\lambda))=\left(h^{*}\right)(g)+\lambda\left(h^{*}\right)(A g)+\lambda^{2}\left(h^{*}\right)\left(A^{2} g\right)+\cdots .
$$

Now $\left(h^{*}\right)(f)^{[n, m]}$ is the Padé Approximant of the above formal power series.

Here we give our basic assumption:

(2.4) There is a positive number $M$, such that for every sequence $x^{(n)} \in S_{g}^{(n)},\left\|x^{(n)}\right\|=1$ there exists a sequence $y^{*(n)} \in T_{h^{*}}^{(n)},\left\|y^{*(n)}\right\|=1$ such that $\left|\left(y^{*(n)}\right)\left(x^{(n)}\right)\right| \geqq M$.

THEOREM. Let $\left\{n^{\prime}\right\} \subset\{n\}$ be a subsequence such that $\left(h^{*}\right)(f)^{\left[n^{\prime}, n^{\prime}+1\right]}$ exists. If (2.4) is fulfilled

$$
\lim _{n^{\prime} \rightarrow \infty}\left(h^{*}\right)(f)^{\left[n^{\prime}, n^{\prime}+1\right]}=\left(h^{*}\right)(f) .
$$

The proof is cut in four parts. In (i) we give a projected equation proposed by Tani [11], Nuttal [9], prove the uniform boundedness of its solutions (ii) and the convergence under the functional $h^{*}$ in (iii). In (iv) is shown, that the last expression is identical to the Padé Approximant of the original equation (2.1).

(i) One defines a series of operators $P^{(n)}: B \rightarrow B, n=0,1,2, \cdots$ 
requiring $P^{(n)}$ and its dual adjoint $P^{(n) *}$ to be projections with

$$
\text { image } P^{(n)}=S_{g}^{(n)}, \quad \text { image } P^{(n)^{*}}=T_{h^{*}}^{(n)} \text {. }
$$

Such an operator $P^{(n)}$ exists if the matrix $c_{i j}^{(n)}=\left(A^{* i} h^{*}\right)\left(A^{j} g\right)$ is invertible; $P^{(n)}$ is unique and can be explicitly written

$$
\forall_{x \in B}, P^{(n)} x=\sum_{i, j=0}^{n} A^{i} g\left(c^{(n)-1}\right)_{i j}\left(A^{* j} h^{*}\right)(x) .
$$

The projected equation is defined as

$$
f^{(n)}=g+\lambda P^{(n)} A f^{(n)} .
$$

One can formally expand $f^{(n)}$ in a power series

$$
f^{n}(\lambda)=g+\lambda P^{(n)} A g+\lambda^{2}\left(P^{(n)} A\right)^{2} g+\cdots .
$$

This Neumann series converges for $|\lambda|<1 /\left\|P^{(n)} A\right\|$. The properties of $P^{(n)}$ imply that the first $n+1$ terms of the expansions on $f(\lambda)$ and $f^{(n)}(\lambda)$ are identical, that $f^{(n)}$ can be written as

$$
f^{(n)}=\sum_{k=0}^{n} f_{k}^{(n)} A^{k} g,
$$

and that an equivalent to definition (2.8) is the set of equations

$$
\left(A^{* k} h^{*}\right)\left(f^{(n)}-g-\lambda A f^{(n)}\right)=0, k=0,1, \cdots, n
$$

which gives an algebraic set of equations in order to determine the coefficients $f_{k}^{(n)}$.

Now let $\left\{n^{\prime}\right\}$ be a subsequence such that $P^{\left(n^{\prime}\right)}$ and $f^{\left(n^{\prime}\right)}$ exist. The existance of $P^{\left(n^{\prime}\right)}$ and $f^{\left(n^{\prime}\right)}$ is guaranteed if the determinant of $c_{i j}^{(n)}$ and the determinant of the algebraique set for $f_{k}^{(n)}$ do not vanish. Baker shows in [1], [2] that either the Padé Approximant of finite order is equal to the exact solution or there exists at least an infinite subsequence $\left\{n^{\prime}\right\}$, such that the determinants for $P^{\left(n^{\prime}\right)}$ and $f^{\left(n^{\prime}\right)}$ do not vanish and thus $P^{\left(n^{\prime}\right)}$ and $f^{\left(n^{\prime}\right)}$ exist. To that subsequence we will confine our attention.

In the following we need the transformation properties of $S_{g}$ and $T_{h^{*}}$ under $(1-\lambda A)^{-1}$ and $\left(1-\lambda A^{*}\right)^{-1}$ respectively,

$$
\begin{aligned}
& (1-\lambda A)^{-1} S_{g} \subset S_{g}, \\
& \left(1-\lambda A^{*}\right)^{-1} T_{h^{*}} \subset T_{h^{*}} .
\end{aligned}
$$

This can be seen as follows. First look upon $(1-\lambda A)^{-1} g$. From the Neumann series one knows $(1-\delta A)^{-1} g=\sum_{k=0}^{\infty}(\delta A)^{k} g \in S_{g}$ for $|\delta|<1 /\|A\|$. In the domain $D=\{\delta|\delta \in C,| \delta \mid<1 /\|A\|\}$ is $(1-\delta A)^{-1}$ an analytic operator in $\delta$. Thus $(1-\delta A)^{-1} g / S_{g}$ is an analytic vector in the quotient space $B / S_{g}$. But $(1-\delta A)^{-1} g / S_{g}=0$ for all $\delta$ in $D$. Then analytic 
continuation gives $(1-\delta A)^{-1} g / S_{g}=0$ for all $\delta \in C$ and thus $(1-\lambda A)^{-1} g \epsilon$ $S_{g}$. Analogously $(1-\lambda A)^{-1} A^{k} g \in S_{g}$ for each $k$ and as $(1-\lambda A)^{-1}$ is continuous in $B$ and $S_{g}$ is closed, the first invariance property follows. Similarly goes the second property.

2.1 reads $f=(1-\lambda A)^{-1} g \in S_{g}$.

(ii) In this section starting from (2.4) we prove the uniform boundedness of solutions of (2.8),

$$
\exists_{K>0},\left\|f^{\left(n^{\prime}\right)}\right\| \leqq K \text {. }
$$

If we assume $\left\{f^{\left(n^{\prime}\right)}\right\}_{n^{\prime}}$ solutions of (2.8) not uniformly bounded, then we have a subsequence $\left\{n^{\prime \prime}\right\} \subset\left\{n^{\prime}\right\}$ such that

$$
u_{n^{\prime \prime}}=1 /\left\|f^{\left(n^{\prime \prime}\right)}\right\|, \lim _{n^{\prime \prime} \rightarrow \infty} u_{n^{\prime \prime}}=0 \text {. }
$$

With the definition $e^{\left(n^{\prime \prime}\right)}=f^{\left(n^{\prime \prime}\right)} /\left\|f^{\left(n^{\prime \prime}\right)}\right\|(2.8)$ reads

$$
\begin{aligned}
e^{\left(n^{\prime \prime}\right)} & =u_{n^{\prime \prime}} g+\lambda P^{\left(n^{\prime \prime}\right)} A e^{\left(n^{\prime \prime}\right)} \\
& =u_{n^{\prime \prime}} g+\lambda\left(P^{\left(n^{\prime \prime}\right)}-1\right) A e^{\left(n^{\prime \prime}\right)}+\lambda A e^{\left(n^{\prime \prime}\right)},
\end{aligned}
$$

which can be rewritten

$$
e^{\left(n^{\prime \prime}\right)}=(1-\lambda A)^{-1}\left(u_{n^{\prime \prime}} g+\lambda\left(P^{\left(n^{\prime \prime}\right)}-1\right) A e^{\left(n^{\prime \prime}\right)}\right) .
$$

Next we have

$$
\forall_{y^{*} \in T_{h^{*}}}, \lim _{n^{\prime \prime} \rightarrow \infty}\left(y^{*}\right)\left(\lambda\left(P^{\left(n^{\prime \prime}\right)}-1\right) A e^{\left(n^{\prime \prime}\right)}\right)=0,
$$

which can be seen as follows. From (2.11) we know that

$$
\left\{\lambda\left(P^{\left(n^{\prime \prime}\right)}-1\right) A \mathrm{e}^{\left(n^{\prime \prime}\right)}\right\}
$$

is uniformly bounded. From the definition of $T_{h^{*}}$ follows the existence of a sequence $y^{*\left(n^{\prime \prime}\right)} \in T_{h^{*}}^{\left(n^{\prime \prime}\right)}$ approximating $y^{*}$ in the norm,

$$
\begin{aligned}
\left|\left(y^{*}\right)\left(\lambda\left(P^{\left(n^{\prime \prime}\right)}-1\right) A e^{\left(n^{\prime \prime}\right)}\right)\right| \leqq & \left\|y^{*}-y^{*\left(n^{\prime \prime}\right)}\right\| \mid\left\|\lambda\left(P^{(n)}-1\right) A e^{\left(n^{\prime \prime}\right)}\right\| \\
& +\left|\left(y^{*\left(n^{\prime \prime}\right)}\right)\left(\lambda\left(P^{\left(n^{\prime \prime}\right)}-1\right) A e^{\left(n^{\prime \prime \prime}\right)}\right)\right| .
\end{aligned}
$$

From (2.6) follows $\forall_{y^{*(n)} \in T_{h^{*}}^{(n)}} P^{(n) *} y^{*(n)}=y^{*(n)}$. Thus the second term is identical 0 .

We apply $y^{*} \in T_{h^{*}}$ to $(2.12)$ :

$$
\begin{aligned}
\forall_{y^{*} \in} T_{h^{*}}^{(n)},\left(y^{*}\right)\left(e^{\left(n^{\prime \prime}\right)}\right) & =\left(y^{*}\right)\left((1-\lambda A)^{-1}\left(u_{n^{\prime \prime}} g+\lambda\left(P^{\left(n^{\prime \prime}\right)}-1\right) A e^{\left(n^{\prime \prime}\right)}\right)\right) \\
& =\left((1-\lambda A)^{-1^{*}} y^{*}\right)\left(u_{n^{\prime \prime}} g+\lambda\left(P^{\left(n^{\prime \prime}\right)}-1\right) A e^{\left(n^{\prime \prime}\right)}\right) \\
& =\left(z^{*}\right)\left(u_{n^{\prime \prime}} g\right)+\left(z^{*}\right)\left(\lambda\left(P^{\left(n^{\prime \prime}\right)}-1\right) A e^{\left(n^{\prime \prime}\right)}\right) .
\end{aligned}
$$

(2.9) guarantees $(1-\lambda A)^{-1^{*}} y^{*}=z^{*} \in T_{h^{*}}$ and the second term tends to 0 because of (2.13), thus leading to 


$$
\forall_{y^{*} \in T_{h^{*}}} \lim _{n^{\prime \prime} \rightarrow \infty}\left(y^{*}\right)\left(e^{\left(n^{\prime \prime}\right)}\right)=0 \text {. }
$$

At this point enters the compactness of $A$. Because $B$ is a Banach space and $\left\|e^{\left(n^{\prime \prime}\right)}\right\|=1$ there is a subsequence $\left\{n^{\prime \prime \prime}\right\} \subset\left\{n^{\prime \prime}\right\}$ and an element $s \in B$ with

$$
\lim _{n^{\prime \prime \prime} \rightarrow \infty}\left\|A e^{\left(n^{\prime \prime \prime}\right)}-s\right\|=0 .
$$

As $S_{g}$ is a closed subspace of $B$, the limit point $s$ is contained in $S_{g}$. Then we find that $\left(y^{*}\right)\left(A e^{\left(n^{\prime \prime \prime}\right)}\right)$ goes to 0 uniformly for $y^{*} \in T_{h^{*}}$, more explicit

$$
\forall_{\varepsilon>0}, \exists_{n_{0}^{\prime \prime \prime}}, \forall_{n^{\prime \prime \prime} \geq_{0}^{\prime \prime \prime}, y^{*} \in T_{h^{*}},|| y^{*} \|=1},\left|\left(y^{*}\right)\left(A e^{\left(n^{\prime \prime \prime}\right)}\right)\right|<\varepsilon .
$$

This can be shown in three steps:

$$
\begin{aligned}
& \forall_{y^{*} \in T_{h^{*}}}\left(y^{*}\right)\left(A e^{\left(n^{\prime \prime \prime}\right)}\right)=\left(A^{*} y^{*}\right)\left(e^{\left(n^{\prime \prime \prime}\right)}\right)=\left(z^{*}\right)\left(e^{\left(n^{\prime \prime \prime}\right)}\right) \\
& \text { and } \lim _{n^{\prime \prime \prime} \rightarrow \infty}\left(z^{*}\right)\left(e^{\left(n^{\prime \prime \prime}\right)}\right)=0 \text { by } 2.14, \\
& \forall_{y^{*} \in T_{h^{*}}}\left(y^{*}\right)(s)=0: \forall_{\varepsilon>0}, \exists_{n_{0}^{\prime \prime \prime},}, \forall_{n^{\prime \prime \prime} \geq n_{0}^{\prime \prime \prime}},\left\|A e^{\left(n^{\prime \prime \prime}\right)}-s\right\|<\varepsilon, \\
& \left|\left(y^{*}\right)(s)\right| \leqq\left\|y^{*}\right\|\left\|s-A e^{\left(n^{\prime \prime \prime}\right)}\right\|+\left|\left(y^{*}\right)\left(A e^{\left(n^{\prime \prime \prime}\right)}\right)\right|<\left\|y^{*}\right\| \varepsilon+\varepsilon, \\
& \forall_{\varepsilon>0}, \exists_{n_{0}^{\prime \prime \prime}}, \forall_{n^{\prime \prime \prime}} \geq n_{n^{\prime \prime}},\left\|A e^{\left(n^{\prime \prime \prime}\right)}-s\right\|<\varepsilon, \\
& \forall_{n^{\prime \prime \prime} \geq n_{0}^{\prime \prime \prime}}, y^{*} \in T_{h^{*}},\left\|y^{*}\right\|=1 \\
& \mid\left(y^{*}\right)\left(A e^{\left(n^{\prime \prime \prime}\right)}|=|\left(y^{*}\right)\left(A e^{\left(n^{\prime \prime \prime}\right)}-s\right)+\left(y^{*}\right)(s) \mid \leqq\left\|y^{*}\right\|\left\|A e^{\left(n^{\prime \prime \prime}\right)}\right\|<\varepsilon .\right.
\end{aligned}
$$

Now we conclude that $\left(y^{*\left(n^{\prime \prime \prime}\right)}\right)\left(e^{\left(n^{\prime \prime \prime}\right)}\right)$ tends to 0 uniformly in $y^{*\left(n^{\prime \prime \prime}\right)} \in T_{h^{*}}^{\left(n^{\prime \prime \prime}\right)}$,

$$
\forall_{\varepsilon>0}, \exists_{n_{0}^{\prime \prime \prime}}, \forall_{n^{\prime \prime \prime} \geqq_{0}^{\prime \prime \prime}, y^{*}\left(n^{\prime \prime \prime}\right)} \in T_{h^{*}}^{\left(n^{\prime \prime \prime}\right)}, \| y^{*\left(n^{\prime \prime \prime \prime}\right) \|=1},\left|\left(y^{*\left(n^{\prime \prime \prime}\right)}\right)\left(e^{\left(n^{\prime \prime \prime}\right)}\right)\right|<\varepsilon .
$$

To see this use (2.11). From (2.10) and (2.16) we have

$$
\begin{aligned}
& \forall_{\varepsilon>0}, \exists_{n_{0}^{\prime \prime \prime}}, \forall_{n^{\prime \prime \prime} \geq n_{0}^{\prime \prime \prime}},\left\|u_{n^{\prime \prime}} \boldsymbol{g}\right\|<\varepsilon, \\
& \forall_{n^{\prime \prime \prime} \geqq n_{0}^{\prime \prime \prime}, y^{*} \in T_{h^{*}},\left\|y^{*}\right\|=1},\left|\left(y^{*}\right)\left(\lambda A e^{\left(n^{\prime \prime \prime}\right)}\right)\right|<\varepsilon|\lambda| .
\end{aligned}
$$

Remembering, that $P^{\left(n^{\prime \prime \prime}\right) *}$ is a projection on $T_{h^{*}}^{\left(n^{\prime \prime \prime}\right)}$, one has

$$
\begin{aligned}
& \forall_{\varepsilon>0}, \exists_{n_{n^{\prime \prime}}^{\prime \prime}}, \forall_{n^{\prime \prime \prime} \geq n_{0}^{\prime \prime \prime}, y^{*}\left(n^{\prime \prime \prime}\right)} \in T_{h^{*}}^{\left(n \prime^{\prime \prime \prime}\right)},\left\|y^{*\left(n^{\prime \prime \prime}\right)}\right\|=1,\left|\left(y^{*\left(n^{\prime \prime \prime}\right)}\right)\left(e^{\left(n^{\prime \prime \prime}\right)}\right)\right| \\
& =\left|\left(y^{*\left(n^{\prime \prime \prime}\right)}\right)\left(u_{n^{\prime \prime}} g\right)+\left(y^{*\left(n^{\prime \prime \prime}\right)}\right)\left(\lambda P^{\left(n^{\prime \prime \prime}\right)} A e^{\left(n^{\prime \prime \prime}\right)}\right)\right| \\
& \leqq\left\|y^{*\left(n^{\prime \prime \prime}\right)}\right\|\left\|u_{n^{\prime \prime \prime}} g\right\|+\left|\left(y^{*\left(n^{\prime \prime \prime}\right)}\right)\left(\lambda A e^{\left(n^{\prime \prime \prime}\right)}\right)\right|<\varepsilon(1+|\lambda|) \text {. }
\end{aligned}
$$

But it is clear that (2.17) contradicts our assumption (2.4).

(iii) Here we will ensure us of the convergence of $\left(h^{*}\right)\left(f^{\left(n^{\prime}\right)}\right)$. We regard (2.8).

$$
f^{\left(n^{\prime}\right)}=g+\lambda P^{\left(n^{\prime}\right)} A f^{\left(n^{\prime}\right)}=g+\lambda\left(P^{\left(n^{\prime}\right)}-1\right) A f^{\left(n^{\prime}\right)}+\lambda A f^{\left(n^{\prime}\right)} .
$$


From the uniform boundedness of $\left\{f^{(x)}\right\}$ we derive the uniform boundedness of $\left\{\lambda\left(P^{\left(n^{\prime}\right)}-1\right) A f^{\left(n^{\prime}\right)}\right\}$ and one has

$$
\forall_{y^{*} \in T_{h^{*}},} \lim _{n^{\prime} \rightarrow \infty}\left(y^{*}\right)\left(\lambda\left(P^{\left(n^{\prime}\right)}-1\right) A f^{\left(n^{\prime}\right)}\right)=0 .
$$

The reason is the same as for (2.13). Investigating the difference of (2.1), (2.8) gives

$$
\begin{aligned}
d^{\left(n^{\prime}\right)} & =f-f^{\left(n^{\prime}\right)}=\lambda\left(A f-P^{\left(n^{\prime}\right)} A f^{\left(n^{\prime}\right)}\right) \\
& =\lambda A d^{\left(n^{\prime}\right)}+\lambda\left(1-P^{\left(n^{\prime}\right)}\right) A f^{\left(n^{\prime}\right)} \\
& =(1-\lambda A)^{-1} \lambda\left(1-P^{\left(n^{\prime}\right)}\right) A f^{\left(n^{\prime}\right)} .
\end{aligned}
$$

We apply $h^{*} \in T_{h^{*}}$

$$
\begin{aligned}
\left(h^{*}\right)\left(d^{\left(n^{\prime}\right)}\right) & =\left(h^{*}\right)\left((1-\lambda A)^{-1} \lambda\left(1-P^{\left(n^{\prime}\right)}\right) A f^{\left(n^{\prime}\right)}\right) \\
& =\left((1-\lambda A)^{-1 *} h^{*}\right)\left(\lambda\left(1-P^{\left(n^{\prime}\right)}\right) A f^{\left(n^{\prime}\right)}\right) \\
& =\left(i^{*}\right)\left(\lambda\left(1-P^{\left(n^{\prime}\right)}\right) A f^{\left(n^{\prime}\right)}\right), \\
\lim _{n^{\prime} \rightarrow \infty}\left(h^{*}\right)\left(d^{\left(n^{\prime}\right)}\right) & =\lim _{n^{\prime} \rightarrow \infty}\left(i^{*}\right)\left(\lambda\left(1-P^{\left(n^{\prime}\right)}\right) A f^{\left(n^{\prime}\right)}\right)=0,
\end{aligned}
$$

which follows from $(1-\lambda A)^{-1^{*}} h^{*}=i^{*} \in T_{h^{*}}$ guaranteed by $(2.9)$ and application of (2.18), hence

$$
\lim _{n^{\prime} \rightarrow \infty}\left(h^{*}\right)\left(f^{\left(n^{\prime}\right)}\right)=\left(h^{*}\right)(f) .
$$

(iv) Finally the relation between $\left(h^{*}\right)\left(f^{\left(n^{\prime}\right)}\right.$ (and the Pade Approximant $\left(h^{*}\right)(f)^{\left[n^{\prime}, n^{\prime}+1\right]}$ has to be established. Some linear algebra shows that $\left(h^{*}\right)\left(f^{\left(n^{\prime}\right)}\right)$ regarded as a function in $\lambda$ is a rational fraction of degree $\left[n^{\prime}, n^{\prime}+1\right]$.

$\left(h^{*}\right)\left(f^{\left(n^{\prime}\right)}\right)^{\left[n^{\prime}, n^{\prime}+1\right]}$ is the Pade Approximant of the formal power series (2.8) under the functional $h^{*}$

$$
\left(h^{*}\right)(g)+\lambda\left(h^{*}\right)\left(P^{\left(n^{\prime}\right)} A g\right)+\lambda^{2}\left(h^{*}\right)\left(\left(P^{\left(n^{\prime}\right)} A\right)^{2} g\right)+\cdots .
$$

If we confer this power series with that of (2.1)

$$
\left(h^{*}\right)(g)+\lambda\left(h^{*}\right)(A g)+\lambda^{2}\left(h^{*}\right)\left(A^{2} g\right)+\cdots .
$$

We find with help of (2.6) the first $2 n^{\prime}+2$ terms to be identical. From the definition (2.3) follows

$$
\left(h^{*}\right)(f)^{\left[n^{\prime}, n^{\prime}+1\right]}=\left(h^{*}\right)\left(f^{\left(n^{\prime}\right)}\right)^{\left[n^{\prime}, n^{\prime}+1\right]} .
$$

Baker [1] shows, that in Hilbert space the coefficients $f_{k}^{(n)}$ in $f^{(n)}=$ $\sum_{k=0}^{n} f_{k}^{(n)} A^{k} g$ constructed from matrix elements $\left(h, A^{m} g\right)$ are rational functions in $\lambda$ of degree $[n, n+1]$. This also applies to the Banach space case, where the coefficients are constructed from $\left(h^{*}\right)\left(A^{m} g\right)$. Then clearly $\left(h^{*}\right)\left(f^{(n)}\right)$ is a rational function in $\lambda$ of degree $[n, n+1]$. 
Zinn-Justin [13] proves that a Padé Approximant $[n, m]$ of a rational fraction of degree $[n, m]$ is identical to the rational fraction. That means

$$
\left(h^{*}\right)\left(f^{\left(n^{\prime}\right)}\right)^{\left[n^{\prime}, n^{\prime}+1\right]}=\left(h^{*}\right)\left(f^{\left(n^{\prime}\right)}\right) .
$$

Thus (2.19), (2.20), (2.1) together give (2.5).

3. Hilbert space formulation. Here we turn to Hilbert space $H=B$, we substitute the adjoint $A^{*}$ by the Hilbert adjoint $A^{+}$of $A$ and every $y^{*} \in H^{*}$ by its isomorphic $y \in H$. Then (2.4) reads

$$
\exists_{M>0}, \forall_{x}(n) \in S_{g}^{(n)},\left\|x^{(n)}\right\|=1, \exists_{y^{(n)} \in T_{h}^{(n)},\left\|y^{(n)}\right\|=1}, \mid\left(y^{(n)}, x^{(n)} \mid \geqq M .\right.
$$

It can be expressed in terms of the aperture of Hilbert spaces [8], [5]. Let $H_{1}, H_{2}$ be closed subspaces of a Hilbert space, $P_{1}, P_{2}$ the related orthogonal projections, $\theta$ is defined as

$$
\theta\left(H_{1}, H_{2}\right)=\left\|P_{1}-P_{2}\right\| \text {. }
$$

In our case $H_{1}=T_{h}^{(n)}, H_{2}=S_{g}^{(n)}, P_{1}=P_{T_{h}^{(n)}}, P_{2}=P_{S_{g}^{(n)}}$.

$$
\theta_{n}=\theta\left(T_{h}^{(n)}, S_{g}^{(n)}\right) \text {. }
$$

Krasnoselskii [5] defines

$$
\tau_{n}=\inf _{t^{(n)} \in T_{h}^{(n)},\|t(n),\|=1}\left\|P_{S_{g}^{(n)}} t^{(n)}\right\|,
$$

and shows

$$
\theta_{n}^{2}+\tau_{n}^{2}=1
$$

We define

$$
\iota_{n}=\inf _{t^{(n)} \in T_{h}^{(n)}, \| t^{n)_{i=1}}} \sup _{s(n) \in S_{g}^{(n)}, \| s(n)_{1 \mid=1}}\left|\left(t^{(n)}, s^{(n)}\right)\right| .
$$

Between $\tau_{n}$ and $\mu_{n}$ the following relation is valid

$$
\tau_{n}^{2} \leqq \mu_{n}<\tau_{n},
$$

which is easy to check. Obviously $0 \leqq \theta_{n}, \tau_{n}, \mu_{n} \leqq 1$ holds, such that we can formulate (3.1) as

$$
\begin{gathered}
\exists_{M>0}, \forall_{\mu_{n}}, \mu_{n}>M \rightleftarrows \inf _{n} \mu_{n}>0 \Longleftrightarrow \inf _{n} \tau_{n}^{2}>0 \\
\Longleftrightarrow \sup _{n} \theta_{n}^{9}<1 \Longleftrightarrow \sup _{n} \theta_{n}<1 .
\end{gathered}
$$

To finish up we illustrate the validity of (3.1). For example take $A$ self adjoint, $C$ is a linear bounded operator commuting with $A$. 


$$
\begin{aligned}
& h=g+C g,\|C\|<1, \\
& \forall_{x^{(n)} \in S_{g}^{(n)},\left\|x^{(n)}\right\|=1}, x^{(n)}=\sum_{i=0}^{n} x_{i}^{(n)} A^{i} g, \\
& v^{(n)}=\sum_{i=0}^{n} x_{i}^{(n)} A^{i} h=\sum_{i=0}^{n} x_{i}^{(n)} A^{i}(g+C g)=x^{(n)}+C x^{(n)}, \\
& y^{(n)}=v^{(n)} /\left\|v^{(n)}\right\|, \\
& \left|\left(y^{(n)}, x^{(n)}\right)\right|=\left|\left(\frac{(1+C) x^{(n)}}{\left\|(1+C) x^{(n)}\right\|}, x^{(n)}\right)\right| \geqq \frac{1-\|C\|}{1+\|C\|} .
\end{aligned}
$$

Thus (3.1) is fulfilled.

ACKNowledgment. I should like to thank Prof. H. Unger and Dr. H. Hilgers, Bonn, for helpful discussions.

\section{REFERENCES}

1. G. A. Baker, Jr., J. Math. Phys. 16, No. 4 (1975).

2. —, J. Math. Anal. Appl., 43 (1973), 498.

3. N. Dunford, J. T. Schwartz, Linear Operators I, II, Interscience, N.Y., 1963.

4. L. D. Faddeev, Mathematical aspects of the three-body problem in the quantum scattering theory, Israel Program for Scientific Translation, Jerusalem, 1965.

5. M. A. Krasnoselskii, G. M. Vainikko, P. P. Zabreiko, Ya. B. Rutitskii, V. Ya. Stetsenko, Approximate Solutions of Operator Equations, Walters-Noordhoff, 1972.

6. M. G. Krein, M. A. Krasnoselskii, Umn 2, No. 3 (1947).

7. _ Mat. Sb., 30, No. 1 (1952).

8. B. Sz. Nagy, Comm. Math. Helv., 19 (1946-47).

9. J. Nuttal, Phys. Rev., 157, 1312 (1967).

10. W. Rudin, Functional Analysis, McGraw Hill, 1973.

11. S. Tani, Phys. Rev., 139, B 1011 (1965), Ann. Phys. (N.Y.) 37 (1966), 411.

12. A. E. Taylor, Introduction to Functional Analysis, John Wiley Inc., N.Y., 1958.

13. J. Zinn-Justin, Strong Interaction Dynamics with Padé Approximants, Service de Physique Théorique, Centre d'Etudes Nucléaires de Saclay, Nov. 1970.

Received April 6, 1977 and revised form July 12, 1979.

UNIVERSITÄT GIESSEN

D-6300 Giessen, West Germany 


\title{
PACIFIC JOURNAL OF MATHEMATICS
}

\section{EDITORS}

\author{
DoNALD BABBITT (Managing Editor) \\ University of California \\ Los Angeles, CA 90024 \\ HUGo RossI \\ University of Utah \\ Salt Lake City, UT 84112 \\ C. C. MOORE and ANDREW OGG \\ University of California \\ Berkeley, CA 94720
}

J. DugundJI

Department of Mathematics

University of Southern California

Los Angeles, CA 90007

R. FINN and J. Milgram

Stanford University

Stanford, CA 94305

\section{ASSOCIATE EDITORS}
E. F. BeCKenbach
B. H. NeumanN
F. WOLF
K. YoshidA

\section{SUPPORTING INSTITUTIONS}

\author{
UNIVERSITY OF BRITISH COLUMBIA \\ CALIFORNIA INSTITUTE OF TECHNOLOGY \\ UNIVERSITY OF CALIFORNIA \\ MONTANA STATE UNIVERSITY \\ UNIVERSITY OF NEVADA, RENO \\ NEW MEXICO STATE UNIVERSITY \\ OREGON STATE UNIVERSITY \\ UNIVERSITY OF OREGON
}

\author{
UNIVERSITY OF SOUTHERN CALIFORNIA \\ STANFORD UNIVERSITY \\ UNIVERSITY OF HAWAII \\ UNIVERSITY OF TOKYO \\ UNIVERSITY OF UTAH \\ WASHINGTON STATE UNIVERSITY \\ UNIVERSITY OF WASHINGTON
}

The Supporting Institutions listed above contribute to the cost of publication of this Journal, but they are not owners or publishers and have no responsibility for its content or policies.

Mathematical papers intended for publication in the Pacific Journal of Mathematics should be in typed form or offset-reproduced, (not dittoed), double spaced with large margins. Please do not use built up fractions in the text of the manuscript. However, you may use them in the displayed equations. Underline Greek letters in red, German in green, and script in blue. The first paragraph or two must be capable of being used separately as a synopsis of the entire paper. Please propose a heading for the odd numbered pages of less than 35 characters. Manuscripts, in triplicate, may be sent to any one of the editors. Please classify according to the scheme of Math. Reviews, Index to Vol. 39. Supply name and address of author to whom proofs should be sent. All other communications should be addressed to the managing editor, or Elaine Barth, University of California, Los Angeles, California, 90024.

50 reprints to each author are provided free for each article, only if page charges have been substantially paid. Additional copies may be obtained at cost in multiples of 50 .

The Pacific Journal of Mathematics is issued monthly as of January 1966. Regular subscription rate: $\$ 84.00$ a year $(6$ Vols., 12 issues). Special rato: $\$ 42.00$ a year to individual members of supporting institutions.

Subscriptions, orders for numbers issued in the last three calendar years, and changes of address shoud be sent to Pacific Journal of Mathematics, P.O. Box 969, Carmel Valley, CA 93924, U.S.A Old back numbers obtainable from Kraus Periodicals Co., Route 100, Millwood, NY 10546.

\section{PUBLISHED BY PACIFIC JOURNAL OF MATHEMATICS, A NON-PROFIT CORPORATION}

Printed at Kokusai Bunken Insatsusha (International Academic Printing Co., Ltd.). 8-8, 3-chome, Takadanobaba, Shinjuku-ku, Tokyo 160, Japan. 


\section{Pacific Journal of Mathematics}

\section{Vol. 86, No. 2 December, 1980}

Graham Donald Allen, David Alan Legg and Joseph Dinneen Ward, Hermitian

liftings in Orlicz sequence spaces ............................... 379

George Bachman and Alan Sultan, On regular extensions of measures ........ 389

Bruce Alan Barnes, Representations Naimark-related to $*$-representations; a

correction: "When is a representation of a Banach $*$-algebra

Naimark-related to a $*$-representation?" ........................ 397

Earl Robert Berkson, One-parameter semigroups of isometries into $H^{p} \ldots \ldots .403$

M. Brodmann, Piecewise catenarian and going between rings ............ 415

Joe Peter Buhler, A note on tamely ramified polynomials ............... 421

William Lee Bynum, Normal structure coefficients for Banach spaces ........ 427

Lung O. Chung, Biharmonic and polyharmonic principal functions ......... 437

Vladimir Drobot and S. McDonald, Approximation properties of polynomials

with bounded integer coefficients .............................

Giora Dula and Elyahu Katz, Recursion formulas for the homology of

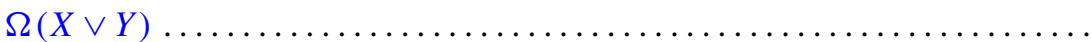

John A. Ernest, The computation of the generalized spectrum of certain Toeplitz operators ...................................... 463

Kenneth R. Goodearl and Thomas Benny Rushing, Direct limit groups and the

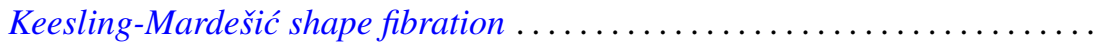

Raymond Heitmann and Stephen Joseph McAdam, Good chains with bad contractions

Patricia Jones and Steve Chong Hong Ligh, Finite hereditary near-ring-semigroups .

Yoshikazu Katayama, Isomorphisms of the Fourier algebras in crossed

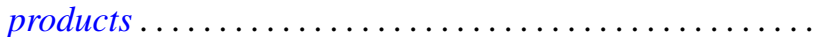

Meir Katchalski and Andrew Chiang-Fung Liu, Symmetric twins and common transversals. .

Mohammad Ahmad Khan, Chain conditions on subgroups of LCA groups ....

Helmut Kröger, Padé approximants on Banach space operator equations ...

Gabriel Michael Miller Obi, An algebraic extension of the Lax-Milgram theorem . .

S. G. Pandit, Differential systems with impulsive perturbation .

Richard Pell, Support point functions and the Loewner variation ...

J. Hyam Rubinstein, Dehn's lemma and handle decompositions of some

4-manifolds

James Eugene Shirey, On the theorem of Helley concerning finite-dimensional subspaces of a dual space.

Oved Shisha, Tchebycheff systems and best partial bases.... 